\title{
Diversidade e potencial biotecnológico da comunidade bacteriana endofítica de sementes de soja
}

\author{
Laura de Castro Assumpção(1), Paulo Teixeira Lacava(1), Armando Cavalcante Franco Dias ${ }^{(2)}$, \\ João Lúcio de Azevedo(1) e José Otávio Machado Menten ${ }^{(3)}$
}

(1)Universidade de São Paulo (USP), Escola Superior de Agricultura Luiz de Queiroz (Esalq), Departamento de Genética, Caixa Postal 83, CEP 13400-970 Piracicaba, SP. E-mail: assumpca@esalq.usp.br, ptlacava@esalq.usp.br, jazevedo@esalq.usp.br (2)USP, Centro de Energia Nuclear na Agricultura, Caixa Postal 96, CEP 13400-970 Piracicaba, SP. E-mail: acfdias@cena.usp.br ${ }^{(3)}$ USP, Esalq, Departamento de Entomologia, Fitopatologia e Zoologia Agrícola. E-mail: jomenten@esalq.usp.br

Resumo - O objetivo deste trabalho foi isolar, caracterizar e identificar a comunidade bacteriana endofítica de sementes de soja e avaliar o seu potencial biotecnológico. Foram utilizadas sementes de 12 cultivares de soja. Os isolados bacterianos endofíticos obtidos foram avaliados in vitro quanto ao antagonismo a fungos fitopatogênicos, síntese de ácido indolacético (AIA) e solubilização de fosfato. A caracterização foi realizada com técnicas de isolamento, análise de restrição do DNA ribossomal amplificado (ARDRA) e sequenciamento parcial do gene 16S rDNA. Os isolados com maior potencial biotecnológico foram inoculados em sementes de soja, para se avaliar a capacidade de promoção de crescimento de plantas. Foi possível identificar 12 ribótipos por meio da ARDRA, que foram classificados como: Acinetobacter, Bacillus, Brevibacterium, Chryseobacterium, Citrobacter, Curtobacterium, Enterobacter, Methylobacterium, Microbacterium, Micromonospora, Pantoea, Paenibacillus, Pseudomonas, Ochrobactrum, Streptomyces e Tsukamurella. Quanto ao potencial biotecnológico da comunidade, $18 \%$ dos isolados controlaram o crescimento de fungos fitopatogênicos, $100 \%$ produziram AIA, e 39\% solubilizaram fosfato. O isolado 67A(57) de Enterobacter sp. aumentou significativamente a massa de matéria seca da raiz. A inoculação de isolados com elevado potencial biotecnológico em avaliações in vitro não promoveu o crescimento de plantas de soja na maioria dos casos.

Termos para indexação: Glycine max, antagonismo, bioprospecção, promoção de crescimento, solubilização de fosfato.

\section{Diversity and biotechnological potential of endophytic bacterial community of soybean seeds}

\begin{abstract}
The objectives of this work were to isolate, characterize and identify the endophytic bacterial community of soybean seeds, and to test the biotechnological potential of this community. Seeds from 12 soybean cultivars were used. The endophytic bacterial isolates were evaluated for in vitro antagonism against phytopathogenic fungi, synthesis of indoleacetic acid (IAA), and capacity to solubilize phosphate. Isolation techniques, amplified ribosomal DNA restriction analysis (ARDRA) grouping, and identification by means of partially sequencing the $16 \mathrm{~S}$ rDNA were used in community characterization. The isolates with best biotechnological potential were inoculated in seeds to evaluate their ability to promote plant growth. Twelve ribotypes were identify by means of ARDRA and classified as: Acinetobacter, Bacillus, Brevibacterium, Chryseobacterium, Citrobacter, Curtobacterium, Enterobacter, Methylobacterium, Microbacterium, Micromonospora, Pantoea, Paenibacillus, Pseudomonas, Ochrobactrum, Streptomyces and Tsukamurella. As for the biotechnological potential of the community, $18 \%$ of the isolates were able to antagonize phytopathogenic fungi, $100 \%$ to synthesize IAA, and $39 \%$ to solubilize phosphate. The strain $67 \mathrm{~A}(57)$ of Enterobacter sp. increased significantly the dry root biomass. Inoculation of promising isolates did not promote growth in soybean plants in most of the cases.
\end{abstract}

Index terms: Glycine max, antagonism, bioprospection, growth promotion, phosphate solubilization.

\section{Introdução}

A cultura da soja, Glycine max (L.) Merrill, tem posição de destaque na agricultura mundial, com rendimento anual de aproximadamente U\$ 215 bilhões. Ultimamente, temse investido muito em pesquisas, para disponibilizar fontes alternativas de nutrientes às plantas, e em metodologias alternativas de controle de patógenos, com enfoque no uso 
de microrganismos endofíticos (Kuss et al., 2007; Barroso \& Nahas, 2008; Ryan et al., 2008; Lucon et al., 2009). Esses microrganismos habitam o interior das plantas e são encontrados em folhas, ramos, raízes e sementes, sem causar doenças às plantas e sem produzir estruturas externas visíveis (Azevedo et al., 2000). A comunidade endofítica é constituída principalmente por fungos e bactérias.

Com o acúmulo de informações sobre a interação planta e microrganismos endofíticos (Sturz et al., 1997; Teixeira et al., 2007; Lacava et al., 2008; Dias et al., 2009) e com a determinação das diferentes funções desses microrganismos no interior das plantas, tem sido dada atenção ao estudo de bactérias endofíticas que podem atuar no controle biológico de inúmeras doenças, na promoção de crescimento vegetal (Hallmann et al., 1997) e na biorremediação de áreas poluídas (Newman \& Reynolds, 2005). Muitas bactérias isoladas de diferentes ecossistemas são promotoras de crescimento de plantas e antagonistas a fitopatógenos e têm sido estudadas para o desenvolvimento de produtos comerciais (Weller et al., 2002), em razão de seu elevado potencial biotecnológico.

Tem havido crescente interesse nos estudos sobre a ocorrência, o potencial de colonização e a utilização de bactérias endofiticas para promoção de crescimento e controle biológico de doenças de plantas (Hallmann et al.,1997; Amorim \& Melo, 2002; Shiomi et al., 2008). As pesquisas indicam que as bactérias endofiticas não estão sujeitas à competição por nutrientes que normalmente ocorre na rizosfera, e têm maior eficiência do que bactérias colonizadoras da rizosfera na promoção do crescimento, absorção de água e na supressão de microrganismos deletérios, em razão de se encontrarem no interior do sistema radicular (Amorim \& Melo, 2002; Santos et al., 2005). Alguns autores enfatizam a necessidade da utilização de isolados residentes ou adaptados ao hospedeiro, pela maior capacidade de colonização e menor risco de introdução de organismo exógenos (Enebak et al., 1998; Khalid et al., 2004).

Este trabalho teve como objetivo isolar, caracterizar e identificar a comunidade bacteriana endofitica de sementes de soja e avaliar o seu potencial biotecnológico.

\section{Material e Métodos}

Sementes de soja de 12 cultivares, fornecidas pela Monsanto do Brasil, foram utilizadas no isolamento bacteriano. As sementes foram submetidas à assepsia superficial (etanol $70 \%$ por $1 \mathrm{~min}$, solução de hipoclorito de sódio $2,5 \%$ por $2 \mathrm{~min}$, etanol $70 \%$ por $1 \mathrm{~min}$ e dois enxágues em água destilada esterilizada), hidratação em água destilada esterilizada (1 hora), trituração e agitação (150 rpm por 1 hora) em tampão fosfato (140 mM de NaCl, $3 \mathrm{mM}$ de KCl, $10 \mathrm{mM}$ de $\mathrm{Na}_{2} \mathrm{HPO}_{4}$ e $2 \mathrm{mM}$ de $\mathrm{KH}_{2} \mathrm{PO}_{4}, \mathrm{pH} 7,4$ ) na proporção de $50 \mathrm{~mL}$ de tampão fosfato para cada $7,5 \mathrm{~g}$ de sementes. Alíquotas de $100 \mu \mathrm{L}$ das suspensões bacterianas foram colocadas em meio de cultura não seletivo "trypic soy broth" (TSB) $10 \%$, digerido pancreático de caseína $17 \mathrm{~g}$, digerido pancreático de semente de soja $3 \mathrm{~g}$, cloreto de sódio $5 \mathrm{~g}$, fosfato de potássio dibásico $2,5 \mathrm{~g}$ e glicose $2,5 \mathrm{~g}$, suplementado com benomil $\left(50 \mu \mathrm{g} \mathrm{mL}^{-1}\right)$, e incubadas a $28^{\circ} \mathrm{C}$ por 15 dias. $\mathrm{O}$ número total de colônias foi utilizado para determinar a densidade bacteriana, em termos de unidades formadoras de colônia por grama de sementes $\left(\mathrm{UFC} \mathrm{g}^{-1}\right)$. Foram realizadas três repetições por cultivar, e cada repetição foi constituída por três placas de Petri com 7,5 g de sementes (Araújo et al., 2002).

Um total de 176 isolados endofiticos bacterianos de sementes de soja foram escolhidos ao acaso e caracterizados genotipicamente, pela técnica de análise de restrição do DNA ribossomal amplificado (ARDRA), tendo-se utilizado a endonuclease MboI (Invitrogen, São Paulo, SP, Brasil), de acordo com as recomendações do fabricante. A clivagem foi confirmada por eletroforese em gel de agarose (2\%). Os perfis de restrição (ribótipos) foram caracterizados pelo número e tamanho dos fragmentos obtidos. Sessenta e dois isolados endofíticos foram identificados pelo sequenciamento parcial do gene $16 \mathrm{~S}$ rDNA, e as sequências foram comparadas com o banco de dados RDPQuery (http://simo.marsci. uga.edu/public_db/rdp_query.htm).

A amplificação do gene $16 \mathrm{~S}$ rDNA dos 62 isolados foi realizada pela técnica de reação em cadeia de polimerase (PCR), com volume de $50 \mu \mathrm{L}$, com $2 \mu \mathrm{L}$ de DNA-molde (aproximadamente $10 \quad \mathrm{ng}), \quad 0,2 \mu \mathrm{M}$ dos iniciadores $\mathrm{P} 027 \mathrm{~F}$ (5'GAGAGTTTGATCCTGGCTCAG-3') e 1378R (5'CGGTGTGTACAAGGCCCGGGAACG-3') (Heuer et al., 1997), $200 \mu \mathrm{M}$ de cada dCTP, dGTP, dATP e dTTP (Invitrogen, São Paulo, SP, Brazil), 3,75 $\mathrm{mM}$ de $\mathrm{MgCl}_{2}, 2,5 \mathrm{U}$ de Taq DNA polimerase (Invitrogen, SP, Brazil) e 1X tampão de Taq DNA polimerase. A PCR foi realizada em termociclador 
(PTC 200, MJ Research) programado para gerar desnaturação inicial de 4 min a $94^{\circ} \mathrm{C}$, seguida de 35 ciclos de $30 \mathrm{~s}$ a $94^{\circ} \mathrm{C}, 1 \mathrm{~min}$ a $62,5^{\circ} \mathrm{C}, 1 \mathrm{~min}$ a $72^{\circ} \mathrm{C}$, e uma extensão final de 7 min a $72^{\circ} \mathrm{C}$. A amplificação do fragmento de aproximadamente $1.400 \mathrm{pb}$ foi confirmada por eletroforese em gel de agarose $(1,2 \%)$.

Os 62 isolados foram avaliados quanto à capacidade antagonista a três gêneros diferentes de fungos fitopatogênicos: Fusarium semitectum (isolado de soja), F. oxysporum (isolado de feijão), F. oxysporum (isolado de algodão), $F$. verticilioides (isolado de milho), Phomopsis sojae (isolado de soja) e Cercospora kikuchii (isolado de soja), pelo método da cultura pareada (Mariano, 1993), para verificação de antagonismos in vitro. Os isolados foram estriados em dois pontos equidistantes, em placas de Petri com meio batata-dextrose-ágar (BDA) - batata $200 \mathrm{~g}$, glucose $20 \mathrm{~g}$ e ágar $15 \mathrm{~g}$-, incubadas a $28^{\circ} \mathrm{C}$. Depois de 48 horas, discos de meio BDA, com as estruturas dos patógenos, foram depositados no centro de cada placa. As placas foram incubadas novamente a $28^{\circ} \mathrm{C}$, por até 72 horas, para que os fungos no tratamento controle (sem isolados) atingissem a borda da placa. Foram considerados quatro tipos de interação entre as bactérias e os fungos: sem inibição (SI); com halo de inibição (HI); com ação fungistática (colônia fúngica com tamanho reduzido ou com produção reduzida de hifas) (AF); e com baixa esporulação (BE).

A produção de AIA foi quantificada pelo método modificado de Bric et al. (1991). As bactérias foram inoculadas em meio de cultura TSB 10\%, suplementado com L-triptofano ( $5 \mathrm{mM})$, e incubadas sob agitação no escuro a $28^{\circ} \mathrm{C}$ por 72 horas. As culturas foram centrifugadas ( 5 min a $10,000 \mathrm{~g}$ ), e $900 \mu \mathrm{L}$ do sobrenadante foi misturado com $400 \mu \mathrm{L}$ do reagente de Salkoviski (Bric et al., 1991). Depois de $30 \mathrm{~min}$ de incubação, à temperatura e luminosidade ambientes, procedeu-se à leitura em espectrofotômetro (Pharmacia Biotech Ultroespec 3000), com comprimento de onda de $530 \mathrm{~nm}$ (Hartmann et al., 1983), normalizada por meio de curva-padrão com diferentes concentrações definidas de AIA comercial. Como controle negativo foi utilizada a bactéria Escherichia coli, linhagem dH5 alfa (Sambrook et al., 1989).

A capacidade de solubilização de fosfato pelos isolados bacterianos foi confirmada pela presença de halo, após o cultivo das bactérias no meio de cultura: glicose, $10 \mathrm{~g} ; \mathrm{Ca}_{3}\left(\mathrm{PO}_{4}\right)_{2}, 5 \mathrm{~g} ; \mathrm{MgCl}_{2}, 0,5 \mathrm{~g}$;
$\mathrm{MgSO}_{4}, 0,25 \mathrm{~g} ; \mathrm{KCl}, 0,2 \mathrm{~g} ;\left(\mathrm{NH}_{4}\right)_{2} \mathrm{SO}_{4}, 0,01 \mathrm{~g}$; azul de bromofenol, 0,025 g; ágar, $15 \mathrm{~g}$ para $1.000 \mathrm{~mL}$ de água destilada, a $28^{\circ} \mathrm{C}$ por 72 horas (Verma et al., 2001).

Para o experimento de promoção de crescimento de plantas em casa de vegetação, sementes de soja cultivar Conquista foram submetidas à assepsia superficial - hipoclorito de sódio $2,5 \%$ diluído $3: 1$ por 3 min (Brasil, 1992) - e imersas nas suspensões bacterianas endofíticas $\left(10^{6} \mathrm{UFC} \mathrm{mL}^{-1}\right)$ dos 17 isolados com melhores resultados nas avaliações in vitro, por uma hora, sob agitação. Quatro sementes, tratadas com cada suspensão bacteriana, foram semeadas por vaso, com $800 \mathrm{~g}$ do substrato comercial PlantMax Hortaliças (Eucatex), e mantidas em casa de vegetação. Após 14 dias, realizou-se desbaste, tendo-se mantido apenas as duas maiores plantas em cada vaso. $\mathrm{O}$ ensaio foi avaliado com 35 dias. O experimento foi conduzido com três controles: controle padrão (sementes infectadas com o isolado EN345 de Pseudomonas oryzihabitans, da coleção de bactérias do Laboratório de Genética de Microrganismos, do Departamento de Genética da Esalq/USP); controle sem inoculação (sementes submetidas à assepsia e incubadas em tampão fosfato, sem bactéria); e testemunha (sementes não submetidas à assepsia, não incubadas em tampão fosfato e sem inoculação de bactéria). Os parâmetros avaliados foram: altura das plantas acima do colo (parte aérea) e massa de matéria fresca e seca da parte aérea e do sistema radicular.

Para os ensaios de antagonismo, produção de AIA e solubilização de fosfato, foi adotado o delineamento experimental inteiramente casualizado, com três repetições. $\mathrm{O}$ ensaio de promoção de crescimento em casa de vegetação foi conduzido em delineamento experimental em blocos ao acaso, com nove repetições e 20 tratamentos. Os dados obtidos foram submetidos à análise de variância, e as médias foram comparadas pelo teste de Tukey, a 5\% de probabilidade. Todas as análises estatísticas foram realizadas com o SAS (SAS Institute, 1989).

\section{Resultados e Discussão}

A caracterização dos isolados endofíticos de sementes de soja, por ARDRA, resultou em 12 ribótipos (Figura 1), e foram identificados 62 isolados por meio do sequenciamento parcial do gene 16S rDNA (Tabela 1) e comparação com o banco de dados 
RDPQuery. Os valores de similaridade variaram entre 97 e $100 \%$.

Nenhum dos isolados bacterianos avaliados apresentou ação antagonista aos fungos $P$. sojae e F. verticilioides. Dos 62 isolados avaliados, 11 (18\%) apresentaram algum tipo de antagonismo a pelo menos um dos seis fungos testados (Tabela 2). Destacaramse dois isolados de Ochrobactrum sp.: 54D(42), com ação sobre quatro fungos fitopatogênicos - F. semitectum (soja), F. oxysporum (feijão), C. kikuchii (soja)e F. oxysporum (algodão); e 53B(59), com ação sobre três fungos $-F$. oxysporum (feijão), C. kikuchii (soja) e F. oxysporum (algodão). Dois isolados do gênero Bacillus sp. apresentaram efeito antagonista a $F$. oxysporum, com diferentes tipos de interação. Cazorla et al. (2007) isolaram, do

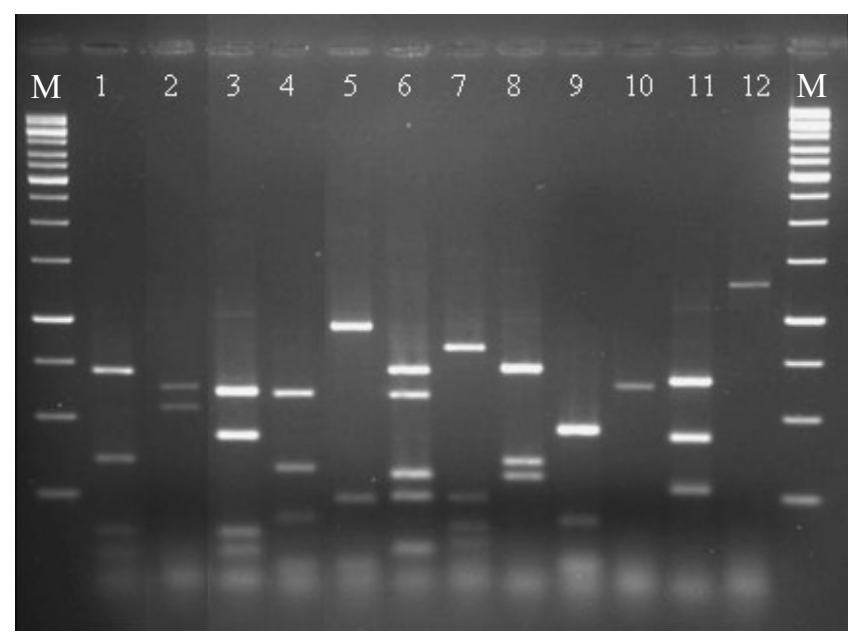

Figura 1. Gel de agarose, com os perfis de bandas dos grupos obtidos pela digestão da reação em cadeia da polimerase (PCR) 16S rDNA com a enzima de restrição $\mathrm{MboI}$. Cada canaleta representa um ribótipo. $\mathrm{M}$, marcador molecular de $1 \mathrm{~kb}$. rizoplano de abacate (Rosellinia necatrix), bactérias identificadas como Bacillus sp. e as caracterizaram como antagonistas a patógenos de plantas, entre eles F. oxysporum. Liu et al. (2007) descreveram isolados de Acinetobacter sp. como antagonistas a diversos fungos fitopatogênicos, entre eles Phytophthora, Rhizoctonia e Fusarium. Resultado semelhante foi observado no presente trabalho, em relação ao gênero Acinetobacter e sua ação antagonista ao fungo F. oxysporum.

Ainda que os testes de antagonismo in vitro nem sempre apresentem o mesmo resultado in vivo (Freitas \& Pizzinatto, 1991), há os que defendem seu uso, com base no fato de que a deteç̧ão de isolados com características antagônicas eficientes pode facilitar uma primeira seleção, já que frequentemente se trabalha com um grande número de isolados (Lucon \& Melo, 1999). Diversos trabalhos têm objetivado obter agentes de controle biológico potencialmente eficientes e, para isso, um grande número de antagonistas tem sido pré-selecionado em testes de antagonismo in vitro, em razão das dificuldades apresentadas pelos métodos de seleção realizados em campo, como: custo, mão de obra, tempo e espaço (Amorim \& Melo, 2002; Shiomi et al., 2008; Lucon et al., 2009).

Os isolados avaliados produziram entre $2,6 \mathrm{e}$ $34,9 \mu \mathrm{g}$ de AIA por mililitro de cultura (Tabela 3). Destacou-se o isolado 33B(8) de Pantoea sp. com a maior produção, enquanto a menor foi observada no isolado $35 \mathrm{~A}(51)$ de Paenibacillus sp. Kuss et al. (2007) obtiveram valores de produção de AIA por bactérias diazotróficas endofíticas (Azospirillum spp.), isoladas de arroz, que variaram entre 2,79 e $13,47 \mu \mathrm{g} \mathrm{mL}^{-1}$, quando quantificados em meio de

Tabela 1. Distribuição e frequência das famílias, nos ribótipos obtidos por ribossomal amplificado (ARDRA) a partir do gene 16S rDNA dos isolados bacterianos endofíticos de sementes de soja.

\begin{tabular}{|c|c|c|c|}
\hline Perfil de ARDRA & Famílias & Gêneros & $\begin{array}{c}\text { Isolados incluídos } \\
\text { nos perfis }(\%)\end{array}$ \\
\hline 1 & Tsukamurellaceae & Tsukamurella & 1,1 \\
\hline 2 & Brucellaceae, Microbacteriaceae e Micrococcineae & Ochrobactrum, Microbacterium e Brevibacterium & 16,5 \\
\hline 3 & Microbacteriaceae & Curtobacterium & 2,3 \\
\hline 4 & Enterobacteriaceae & Pantoea & 2,3 \\
\hline 5 & Moraxellaceae e Methylobacteriaceae & Acinetobacter e Methylobacterium & 35,2 \\
\hline 6 & Enterobacteriacea & Enterobacter e Citrobacter & 5,7 \\
\hline 7 & Paenibacillaceae & Paenibacillus & 6,2 \\
\hline 8 & Bacillaceae & Bacillus & 11,9 \\
\hline 9 & Bacillaceae & Bacillus & 10,2 \\
\hline 10 & Pseudomonadaceae e Flavobacteriaceae & Pseudomonas e Chryseobacterium & 7,4 \\
\hline 11 & Streptomycetaceae & Streptomyces & 0,6 \\
\hline 12 & Micromonosporaceae & Micromonospora & 0,6 \\
\hline
\end{tabular}


cultura, enquanto Selvakumar et al. (2008) isolaram Bacillus sp. e Enterobacter sp. de nódulos de kudzu (Pueraria thunbergiana), capazes de produzir $6,5 \mu \mathrm{g} \mathrm{mL}^{-1}$ de AIA e de promover o crescimento de plântulas de trigo, evidenciado pelo aumento da altura e da biomassa das raízes das plântulas.

Quanto à capacidade de solubilização de fosfatos, entre os 62 inoculados avaliadas, 24 (39\%) formaram halo (Tabela 3). O maior halo de solubilização de fosfato foi observado no isolado $67 \mathrm{~A}(57)$ de Enterobacter sp., com $8,3 \mathrm{~cm}$, e o menor no isolado $122 \mathrm{D}(61)$ de Acinetobacter sp., com $0,2 \mathrm{~cm}$. Diversos gêneros bacterianos têm sido descritos como solubilizadores de fosfato, entre eles Pseudomonas, Bacillus, Rhizobium, Burkholderia, Achromobacter, Agrobacterium, Microccocus, Flavobacterium e Erwinia (Rodriguez \& Fraga, 1999). O fósforo é um dos principais nutrientes para as plantas. Entretanto, grande parte desse nutriente presente no solo, aproximadamente 95-99\%, está na forma insolúvel e não pode ser prontamente utilizado pelas plantas (Vassileva et al., 1998). $\mathrm{O}$ uso de inoculantes com bactérias solubilizadoras de fosfato (BSF) representa uma alternativa para aumentar a eficiência da adubação com fosfatos solúveis e diminuir os custos de produção (Rajankar

Tabela 2. Tipos de interação entre os isolados bacterianos endofíticos de sementes de soja e fungos fitopatogênicos.

\begin{tabular}{|c|c|c|c|}
\hline Isolados bacterianos & Gêneros bacterianos & Fungos & Tipo de interação $^{(1)}$ \\
\hline $11 \mathrm{~B}(2)$ & Brevibacterium & Cercospora kikuchii (soja) & $\mathrm{HI}$ \\
\hline $3 \mathrm{C}(6)$ & Microbacterium & Fusarium oxysporum (algodão) & $\mathrm{BE}$ \\
\hline $80 \mathrm{~A}(13)$ & Acinetobacter & F. oxuysporum (algodão) & $\mathrm{AF}+\mathrm{BE}$ \\
\hline $43 \mathrm{~A}(25)$ & Bacillus & F. oxysporum (algodão) & $\mathrm{AF}$ \\
\hline $91 \mathrm{~A}(29)$ & Acinetobacter & C. kikuchii (soja) & $\mathrm{AF}$ \\
\hline $54 \mathrm{D}(42)$ & Ochrobactrum & F. semitectum (soja) & $\mathrm{AF}$ \\
\hline $54 \mathrm{D}(42)$ & Ochrobactrum & F. oxysporum (feijão) & $\mathrm{AF}$ \\
\hline $54 \mathrm{D}(42)$ & Ochrobactrum & C. kikuchii (soja) & $\mathrm{AF}$ \\
\hline $54 \mathrm{D}(42)$ & Ochrobactrum & F. oxysporum (algodão) & $\mathrm{AF}+\mathrm{BE}$ \\
\hline $129 B(46)$ & Acinetobacter & F. oxysporum (algodão) & $\mathrm{AF}+\mathrm{BE}$ \\
\hline $41 \mathrm{~B}(52)$ & Bacillus & F.oxysporum (algodão) & $\mathrm{BE}$ \\
\hline $4 \mathrm{E}(7)$ & Microbacterium & F. oxysporum (algodão) & $\mathrm{BE}$ \\
\hline $56 \mathrm{~B}(44)$ & Ochrobactrum & F. oxysporum (algodão) & $\mathrm{BE}$ \\
\hline $53 \mathrm{~B}(59)$ & Ochrobactrum & F. oxysporum (feijão) & $\mathrm{AF}$ \\
\hline $53 \mathrm{~B}(59)$ & Ochrobactrum & C. kikuchii (soja) & $\mathrm{AF}$ \\
\hline $53 \mathrm{~B}(59)$ & Ochrobactrum & F. oxysporum (algodão) & $\mathrm{AF}+\mathrm{BE}$ \\
\hline
\end{tabular}

${ }^{(1)} \mathrm{HI}$ : com halo de inibição; AF: com ação fungistática; BE: com baixa esporulação.

Tabela 3. Identificação e características dos isolados bacterianos selecionados para o ensaio de promoção de crescimento de plantas de soja em casa de vegetação.

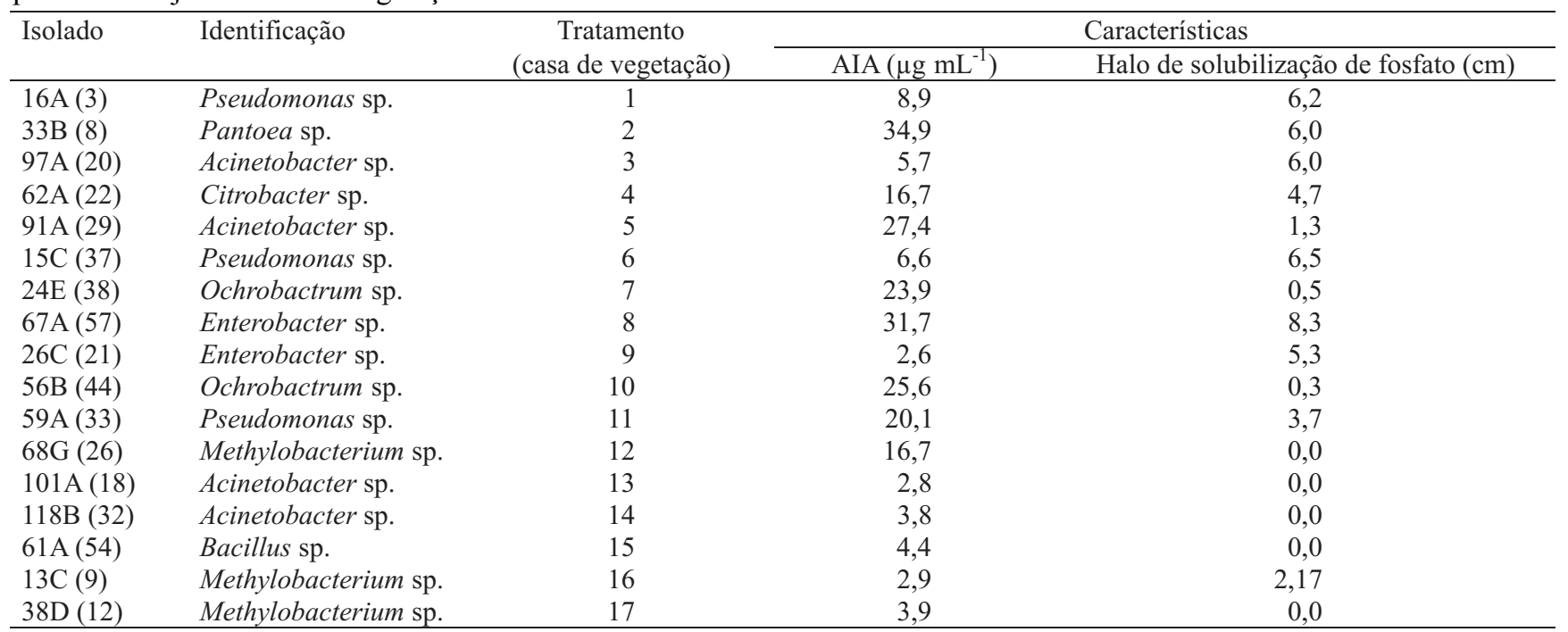


et al., 2007; Barroso \& Nahas, 2008). Microrganismos endofíticos representam uma importante fonte para o desenvolvimento de inoculantes, pois podem interagir de diferentes maneiras com a planta hospedeira. A característica de promoção de crescimento vegetal, relacionada à solubilização de fosfato, é particularmente importante (Ryan et al., 2008; Dias et al., 2009).

Ainoculação do isolado 67A(57) de Enterobactersp. nas plantas de soja determinou aumento significativo da biomassa seca de raiz (Tabela 4). Esse isolado apresentou alta produção de AIA in vitro e, também, o maior halo no meio de cultura para detecção da capacidade de solubilização de fosfato (Tabela 3 ). A inoculação do isolado $26 \mathrm{C}(21)$ de Enterobacter $\mathrm{sp}$. teve efeito negativo sobre a biomassa fresca de raiz e biomassa fresca total, com tendência, no entanto, de aumento da biomassa (fresca e seca) da parte aérea das plantas (Tabela 4). Com o isolado 24E(38) de Ochrobactrum sp. houve tendência de aumento de todos os parâmetros avaliados, embora não tenha diferido estatisticamente do controle não inoculado (Tabela 4). Também com o isolado 15C(37) de Pseudomonas sp. houve tendência de aumento da biomassa seca da parte aérea e da biomassa seca da raiz (Tabela 4).

Os resultados obtidos reforçam a ideia de que a promoção de crescimento de plantas é um fenômeno complexo que é alcançado pela atividade simultânea de vários microrganismos e fatores (Lifshitz et al., 1987). O fato de os tratamentos não terem, em sua maioria, promovido o crescimento de plantas pode ser atribuído a diversos fatores: estresse sofrido pelas sementes durante a assepsia; eliminação dos microrganismos epifíticos; e pequenas variações no balanço da população bacteriana endofítica, que pode ter causado um desequilíbrio entre os microrganismos benéficos e os deletérios (Whipps, 2001).

Os efeitos benéficos da inoculação de bactérias em plantas e sementes, com vistas à promoção de crescimento vegetal, já estão bem discutidos e documentados (Naik et al., 2008; Ryan et al., 2008), embora o processo de bacterização de tecidos vegetais possa gerar efeitos deletérios ou nulos, em relação ao desenvolvimento da planta, como mostrado por Probanza et al. (1996), sobre o efeito negativo de Bacillus subtilis no comprimento da parte aérea e de raízes de pínus (Pinus taeda L.), e de Pseudomonas fluorescens sobre o crescimento de amieiro (Alnus glutinosa). Santos et al. (2005) também observaram o efeito negativo de diferentes espécies de bactérias endofíticas e epifíticas sobre o desenvolvimento de unidades propagativas de helicônia (Heliconia psittacorum L.f.).

Tabela 4. Efeito da inoculação de bactérias endofíticas em sementes de soja, no desenvolvimento de plantas, aos 35 dias ${ }^{(1)}$.

\begin{tabular}{|c|c|c|c|c|c|c|c|c|}
\hline $\begin{array}{l}\text { Tratamento } \\
\text { (isolado bacteriano) }\end{array}$ & Identificação & $\begin{array}{c}\text { Altura da } \\
\text { parte aérea } \\
(\mathrm{cm})\end{array}$ & $\begin{array}{c}\text { Biomassa fresca } \\
\text { da parte aérea } \\
(\mathrm{g})\end{array}$ & $\begin{array}{c}\text { Biomassa seca } \\
\text { da parte aérea } \\
(\mathrm{g})\end{array}$ & $\begin{array}{c}\text { Biomassa } \\
\text { fresca de raiz } \\
(\mathrm{g})\end{array}$ & $\begin{array}{c}\text { Biomassa } \\
\text { seca de raiz } \\
(\mathrm{g}) \\
\end{array}$ & $\begin{array}{c}\text { Biomassa } \\
\text { fresca total } \\
(\mathrm{g})\end{array}$ & $\begin{array}{c}\text { Biomassa } \\
\text { seca total } \\
(\mathrm{g}) \\
\end{array}$ \\
\hline $16 \mathrm{~A}(3)$ & Pseudomonas sp. & $15,32 b$ & $1,23 \mathrm{bc}$ & $0,26 \mathrm{c}$ & $1,69 \mathrm{fg}$ & 0,14 bcdef & $2,81 \mathrm{efg}$ & $0,41 b c$ \\
\hline $33 \mathrm{~B}(8)$ & Pantoea sp. & $17,07 \mathrm{ab}$ & $1,59 \mathrm{ab}$ & $0,36 a b c$ & $1,95 \mathrm{cdefg}$ & $0,17 \mathrm{ab}$ & $2,57 \mathrm{bcdef}$ & $0,53 \mathrm{ab}$ \\
\hline $97 \mathrm{~A}(20)$ & Acinetobacter sp. & $16,93 \mathrm{ab}$ & $1,47 \mathrm{abc}$ & $0,34 a b c$ & 2,41abcd & 0,15 abcdef & $3,88 \mathrm{bcde}$ & $0,50 \mathrm{ab}$ \\
\hline $62 \mathrm{~A}(22)$ & Citrobacter sp. & $17,79 \mathrm{ab}$ & $1,62 \mathrm{ab}$ & $0,38 \mathrm{a}$ & $1,83 \mathrm{defg}$ & $0,16 a b c d$ & 3,51bcdefg & $0,54 \mathrm{ab}$ \\
\hline $91 \mathrm{~A}(29)$ & Acinetobacter sp. & $17,43 \mathrm{ab}$ & $1,61 \mathrm{a}$ & $0,37 \mathrm{a}$ & $2,25 \mathrm{bcdef}$ & $0,17 \mathrm{ab}$ & $3,85 \mathrm{abcde}$ & $0,55 \mathrm{a}$ \\
\hline $15 \mathrm{C}(37)$ & Pseudomonas sp. & $18,50 \mathrm{ab}$ & $1,60 \mathrm{ab}$ & $0,38 \mathrm{a}$ & $2,45 \mathrm{abcd}$ & 0,16 abcde & $4,14 \mathrm{abc}$ & $0,54 \mathrm{ab}$ \\
\hline $24 \mathrm{E}(38)$ & Ochrobactrum sp. & $18,75 \mathrm{a}$ & $1,74 \mathrm{a}$ & $0,38 \mathrm{a}$ & $2,97 \mathrm{a}$ & $0,16 a b c$ & $4,73 \mathrm{a}$ & $0,54 \mathrm{a}$ \\
\hline $67 \mathrm{~A}(57)$ & Enterobacter sp. & $17,71 \mathrm{ab}$ & $1,61 \mathrm{ab}$ & $0,37 \mathrm{ab}$ & 2,36abcde & $0,19 \mathrm{a}$ & 3,99abcd & $0,56 \mathrm{a}$ \\
\hline $26 \mathrm{C}(21)$ & Enterobacter sp. & $17,43 \mathrm{ab}$ & $1,66 \mathrm{a}$ & $0,39 \mathrm{a}$ & $1,62 \mathrm{fg}$ & 0,13 bcdefg & $3,28 \mathrm{cdefg}$ & $0,52 \mathrm{ab}$ \\
\hline $56 \mathrm{~B}(44)$ & Ochrobactrum sp. & $17,33 \mathrm{ab}$ & $1,64 \mathrm{ab}$ & $0,37 \mathrm{abc}$ & 2,39abcd & 0,16 abcdef & 3,78 abcde & $0,50 \mathrm{ab}$ \\
\hline $59 \mathrm{~A}(33)$ & Pseudomonas sp. & $18,07 \mathrm{ab}$ & $1,37 \mathrm{abc}$ & $0,32 \mathrm{abc}$ & $1,65 \mathrm{fg}$ & 0,12 defgh & $3,18 \mathrm{cdefg}$ & $0,44 \mathrm{abc}$ \\
\hline $68 \mathrm{G}(26)$ & Methylobacterium sp. & $17,79 \mathrm{ab}$ & $1,61 \mathrm{ab}$ & $0,37 \mathrm{a}$ & $1,68 \mathrm{efg}$ & 0,13 cdefgh & 3,32 cdefg & $0,50 \mathrm{ab}$ \\
\hline $101 \mathrm{~A}(18)$ & Acinetobacter sp. & $17,57 \mathrm{ab}$ & $1,60 \mathrm{ab}$ & $0,36 a b c$ & $1,95 \mathrm{cdefg}$ & 0,12 cdefgh & 3,48 bcdefg & $0,48 \mathrm{abc}$ \\
\hline $118 \mathrm{~B}(32)$ & Acinetobacter sp. & $15,50 \mathrm{~b}$ & $1,16 \mathrm{c}$ & $0,27 \mathrm{bc}$ & $1,31 \mathrm{~g}$ & $0,09 \mathrm{~h}$ & $2,47 \mathrm{~g}$ & $0,36 \mathrm{c}$ \\
\hline $61 \mathrm{~A}(54)$ & Bacillus sp. & $17,86 \mathrm{ab}$ & $1,42 \mathrm{abc}$ & $0,35 \mathrm{abc}$ & $1,33 \mathrm{~g}$ & $0,11 \mathrm{fgh}$ & $2,70 \mathrm{fg}$ & $0,44 \mathrm{abc}$ \\
\hline $13 \mathrm{C}(9)$ & Methylobacterium sp. & $16,57 \mathrm{ab}$ & $1,43 a b c$ & $0,32 \mathrm{abc}$ & $1,28 \mathrm{~g}$ & $0,11 \mathrm{gh}$ & $2,70 \mathrm{fg}$ & $0,44 \mathrm{abc}$ \\
\hline $38 \mathrm{D}(12)$ & Methylobacterium sp. & $16,04 \mathrm{ab}$ & $1,48 \mathrm{abc}$ & $0,34 \mathrm{abc}$ & $1,48 \mathrm{~g}$ & $0,12 \mathrm{efgh}$ & 2,99defg & $0,45 \mathrm{abc}$ \\
\hline Controle padrão & P. oryzihabitans (EN 345) & $16,67 \mathrm{ab}$ & $1,53 \mathrm{abc}$ & $0,36 a b c$ & $2,52 \mathrm{abc}$ & $0,15 \mathrm{bcdefg}$ & 4,00abcd & $0,50 \mathrm{ab}$ \\
\hline Controle sem inoculação & - & $15,71 \mathrm{ab}$ & $1,48 \mathrm{abc}$ & $0,34 \mathrm{abc}$ & $2,90 \mathrm{ab}$ & 0,15 bcdefg & $4,43 \mathrm{ab}$ & $0,50 \mathrm{ab}$ \\
\hline Testemunha & - & $18,21 \mathrm{ab}$ & $1,68 \mathrm{a}$ & $0,41 \mathrm{a}$ & $2,55 \mathrm{abc}$ & 0,16 abcde & $4,16 a b c$ & $0,56 \mathrm{a}$ \\
\hline Média & - & 17,21 & 1,53 & 0,35 & 2,03 & 0,14 & 3,50 & 0,49 \\
\hline Desvio-padrão & - & 1,66 & 0,20 & 0,05 & 0,33 & 0,02 & 0,51 & 0,06 \\
\hline
\end{tabular}

${ }^{(1)}$ Valores nas colunas seguidos de letras iguais não diferem entre si pelo teste de Tukey, a 5\% de probabilidade. 


\section{Conclusões}

1. A comunidade bacteriana endofítica cultivável de sementes de soja compreende os gêneros: Acinetobacter, Bacillus, Brevibacterium, Chryseobacterium, Citrobacter, Curtobacterium, Enterobacter, Methylobacterium, Microbacterium, Micromonospora, Pantoea, Paenibacillus, Pseudomonas, Ochrobactrum, Streptomyces e Tsukamurella.

2. Os isolados bacterianos endofíticos de sementes de soja são capazes de sintetizar ácido indolacético, solubilizar fosfato e inibir o crescimento e esporulação de fungos fitopatogênicos, mas não promoveram o crescimento de plantas de soja na maioria dos casos.

\section{Agradecimentos}

À Coordenação de Aperfeiçoamento de Pessoal de Nível Superior, pela bolsa concedida; e à Monsanto do Brasil Ltda., por ceder as sementes de soja.

\section{Referências}

AMORIM, E.P. da R.; MELO, I.S. de. Ação antagônica de rizobactérias contra Phytophthora parasitica e P. citrophthora e seu efeito no desenvolvimento de plântulas de citros. Revista Brasileira de Fruticultura, v.24, p.565-568, 2002.

ARAÚJO, W.L.; MARCON, J.; MACCHERONI JUNIOR, W.; ELSAS, J.D. van; VUURDE, J.W.L. van; AZEVEDO, J.L. Diversity of endophytic bacterial populations and their interaction with Xylella fastidiosa in citrus plants. Applied and Environmental Microbiology, v.68, p.4906-4914, 2002.

AZEVEDO, J.L.; MACCHERONI JÚNIOR, W.; PEREIRA, J.O.; ARAÚJO, W.L. de. Endophytic microorganisms: a review on insect control and recent advances on tropical plants. Electronic Journal of Biotechnology, v.3, p.40-65, 2000.

BARROSO, C.B.; NAHAS, E. Solubilização do fosfato de ferro em meio de cultura. Pesquisa Agropecuária Brasileira, v.43, p.529-535, 2008.

BRASIL. Ministério da Agricultura, Pecuária e Abastecimento. Regras para análise de sementes. Brasília: Departamento Nacional de Produção Vegetal, 1992. 365p.

BRIC, J.M.; BOSTOCK, R.M.; SILVERSTONE, S.E. Rapid in situ assay for indoleacetic acid production by bacteria immobilized on a nitrocellulose membrane. Applied and Environmental Microbiology, v.57, p.535-538, 1991.

CAZORLA, F.M.; ROMERO, D.; PEREZ-GARCIA, A.; LUGTENBERG, B.J.J.; DE VICENTE, A.; BLOEMBERG, G. Isolation and characterization of antagonistic Bacillus subtilis strains from the avocado rhizoplane displaying biocontrol activity. Journal of Applied Microbiology, v.103, p.1950-1959, 2007.

DIAS, A.C.F.; COSTA, F.E.C.; ANDREOTE, F.D.; LACAVA, P.T.; TEIXEIRA, M.A.; ASSUMPÇÃO, L.C.; ARAÚJO, W.L.;
AZEVEDO, J.L.; MELO, I.S. Isolation of micropropagated strawberry endophytic bacteria and assessment of their potential for plant growth promotion. World Journal of Microbiology and Biotechnology, v.25, p.189-195, 2009.

ENEBAK, S.A.; WEI, G.; KLOEPPER, J.W. Effects of plant growth-promoting rhizobacteria on loblolly and slash pine seedlings. Forest Science, v.44, p.139-144, 1998.

FREITAS, S.S.;PIZZINATTO, M.A. Interações de Pseudomonas sp. e Fusarium oxysporum f. sp. lycopersici na rizosfera de tomateiro (Lycopersicon esculentum). Summa Phytopathologica, v.17, p.105-112, 1991.

HALLMANN, J.; QUADT-HALLMANN, A.; MAHAFFEE, W.F.; KLOEPPER, J.W. Bacterial endophytes in agricultural crops. Canadian Journal of Microbiology, v.43, p.895-914, 1997.

HARTMANN, A.; SINGH, M.; KLINGMULLER, W. Isolation and characterization of Azospirillum mutants excreting high amounts of indoleacetic acid. Canadian Journal of Microbiology, v.29, p.916-923, 1983.

HEUER, H.; KRSEK, M.; BAKER, P.; SMALLA, K.; WELLINGTON, E.M.H. Analysis of actinomycete communities by specific amplification of genes encoding $16 \mathrm{~S}$ rRNA and gel-electrophoretic separation in denaturing gradients. Applied and Environmental Microbiology, v.63, p.3233-3241, 1997.

KHALID, A.; ARSHAD, M.; ZAHIR, Z.A. Screening plant growth-promoting rhizobacteria for improving growth and yield of wheat. Journal of Applied Microbiology, v.96, p.473-480, 2004.

KUSS, A.V.; KUSS, V.V.; LOVATO, T.; FLÔRES, M.L. Fixação de nitrogênio e produção de ácido indolacético in vitro por bactérias diazotróficas endofíticas. Pesquisa Agropecuária Brasileira, v.42, p.1459-1465, 2007.

LACAVA, P.T.; SILVA-STENICO, M.E.; ARAÚJO, W.L.; SIMIONATO, A.V.C.; CARRILHO, E.; TSAI, S.M.; AZEVEDO, J.L. Detection of siderophores in endophytic bacteria Methylobacterium spp. associated with Xylella fastidiosa subsp. pauca. Pesquisa Agropecuária Brasileira, v.43, p.521-528, 2008.

LIFSHITZ, R.; KLOEPPER, J.W.; KOZLOWSKI, M.; SIMONSON, C.; CARLSON, J.; TIPPING, E.M.; ZALESKA, I. Growth promotion of canola (rape-seed) seedlings by a strain of Pseudomonas putida under gnotobiotic conditions. Canadian Journal of Microbiology, v.33, p.390-395, 1987.

LIU, C.H.; CHEN, X.; LIU, T.T.; LIAN, B.; GU, Y.; CAER, V.; XUE, Y.R.; WANG, B.T. Study of the antifungal activity of Acinetobacter baumannii LCH001 in vitro and identification of its antifungal components. Applied Microbiology and Biotechnology, v.76, p.459-466, 2007.

LUCON, C.M.M.; KOIKE, C.M.; ISHIKAWA, A.I.; PATRÍCIO, F.R.A.; HARAKAVA, R. Bioprospecção de isolados de Trichoderma spp. para o controle de Rhizoctonia solani na produção de mudas de pepino. Pesquisa Agropecuária Brasileira, v.44, p.225-232, 2009.

LUCON,C.M.M.; MELO,I.S. Seleção derizobactérias antagônicas a Erwinia carotovora subsp. atroseptica, em tubérculos de batata. Summa Phytopathologica, v.25, p.132-136, 1999. 
MARIANO, R.L.R. Métodos de seleção in vitro para o controle microbiológico de patógenos de plantas. In: LUZ, W.C. da; FERNANDES, J.M.C.; PRESTES, A.M.; PICININI, E.C. (Ed.). Revisão anual de patologia de plantas. Passo Fundo: Revisão Anual de Patologia de Plantas, 1993. p.369-409.

NAIK, B.S.; SHASHIKALA, J.; KRISHNAMURTHY, Y.L. Host growth characteristics influenced by seed inoculation with microorganisms. World Journal of Agricultural Sciences, v.4, p.891-895, 2008.

NEWMAN, L.A.; REYNOLDS, C.M. Bacteria and phytoremediation: new uses for endophytic bacteria in plants. Trends in Biotechnology, v.23, p.6-8, 2005.

PROBANZA, A.; LUCAS, J.A.; ACERO, N.; MANERO, F.J.G. The influence of native rhizobacteria on European alder (Alnus glutinosa (L.) Gaertn.) growth. 1. Characterization of growth promoting and growth inhibiting bacterial strains. Plant and Soil, v.182, p.59-66, 1996.

RAJANKAR, P.N.; TAMBEKAR, D.H.; WATE, S.R. Study of phosphate solubilization efficiencies of fungi and bacteria isolated from saline belt of Purna river basin. Research Journal of Agriculture and Biological Sciences, v.3, p.701-703, 2007.

RODRIGUEZ, H.; FRAGA, R. Phosphate solubilizing bacteria and their role in plant growth promotion. Biotechnology Advances, v.17, p.319-339, 1999.

RYAN, R.P.; GERMAINE, K.; FRANKS, A.; RYAN, D.J.; DOWLING, D.N. Bacterial endophytes: recent developments and applications. FEMS Microbiology Letters, v.278, p.1-9, 2008.

SAMBROOK, J.; FRITSCH, E.F.; MANIATIS, T. Molecular cloning: a laboratory manual. 2.ed. New York: Cold Spring Harbor Laboratory Press, 1989. 3v.

SANTOS, M.H.L.C.; MARIANO, R. de L.R.; CAMARA, T.R.; ANDRADE, A.G. de; WILLADINO, L.; LIMA, G.P.P. Bactérias promotoras de crescimento no desenvolvimento de Heliconia psittacorum L.f. Hoehnea, v.32, p.1-8, 2005.

SAS INSTITUTE. Statistical analizys sustems user's guide. Cary: SAS Institute, 1998.

SELVAKUMAR, G.; KUNDU, S.; GUPTA, A.D.; SHOUCHE, Y.S.; GUPTA, H.S. Isolation and characterization of nonrhizobial plant growth promoting bacteria from nodules of kudzu (Pueraria thunbergiana) and their effect on wheat seedling growth. Current Microbiology, v.56, p.134-139, 2008.

SHIOMI, H.F.; MELO, I.S. de; MINHONI, M.T. de A. Seleção de bactérias endofíticas com ação antagônica a fitopatógenos. Scientia Agraria, v.9, p.535-538, 2008.

TEIXEIRA, M.A.; MELO, I.S. de; VIEIRA, R.F.; COSTA, F.E. de C.; HARAKAVA, R. Microrganismos endofíticos de mandioca de áreas comerciais e etnovariedades em três estados brasileiros. Pesquisa Agropecuária Brasileira, v.42, p.43-49, 2007.

VASSILEVA, M.; VASSILEV, N.; AZCON, R. Rock phosphate solubilization by Aspergillus niger on olive cake-based medium and its further application in a soil-plant system. World Journal of Microbiology and Biotechnology, v.14, p.281-284, 1998.

VERMA, S.C.; LADHA, J.K.; TRIPATHI, A.K. Evaluation of plant growth promoting and colonization ability of endophytic diazotrophs from deep water rice. Journal of Biotechnology, v.91, p.127-141, 2001.

WELLER, D.M.; RAAIJMAKERS, J.M.; GARDENER, B.B.M.; THOMASHOW, L.S. Microbial populations responsible for specific soil suppressiveness to plant pathogens. Annual Review of Phytopathology, v.40, p.309-348, 2002.

WHIPPS, J.M. Microbial interactions and biocontrol in the rhizosphere. Journal of Experimental Botany, v.52, p.487-511, 2001.

Recebido em 27 de novembro de 2008 e aprovado em 28 de abril de 2009 